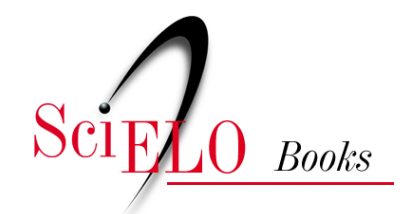

EDUFU

\title{
As oficinas de teatro e a prática do artista-docente
}

\author{
Narciso Telles
}

TELLES, N. As oficinas de teatro e a prática do artista-docente. In: FLORENTINO, A., and TELLES, N., eds. Cartografias do ensino do teatro [online]. Uberlândia: EDUFU, 2008, pp. 233-238. ISBN 978-85-7078-518-3. https://doi.org/10.7476/9788570785183.0024.

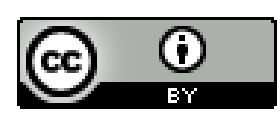

All the contents of this work, except where otherwise noted, is licensed under a Creative Commons Attribution 4.0 International license.

Todo o conteúdo deste trabalho, exceto quando houver ressalva, é publicado sob a licença Creative Commons Atribição $\underline{4.0}$.

Todo el contenido de esta obra, excepto donde se indique lo contrario, está bajo licencia de la licencia $\underline{\text { Creative Commons }}$ Reconocimento 4.0. 


\section{As OFICINAS DE TEATRO E A PRÁTICA DO ARTISTA-DOCENTE}

Narciso Telles

Os cursos de licenciatura em teatro, muitos originados dos "antigos" cursos de Educação Artística, habilitação em Artes Cênicas, formam, basicamente, professores de teatro para atuarem, prioritariamente, nas salas de aula das escolas de educação básica. Pouco pensamos na formação deste licenciando e sua atuação em espaços estritamente de formação teatral, como as escolas técnicas e profissionalizantes ou ainda no bacharel em teoria, interpretação, direção ou cenografia que, por uma demanda, acaba trabalhando como professor. Assim, este texto apresenta reflexões sobre os processos de ensino-aprendizagem desenvolvidos por grupos teatrais brasileiros, na perspectiva de apontar novos caminhos de atuação profissional para os bacharéis e licenciados em teatro que desenvolvem atividades em espaços formais e informais de ensino.

Para tanto, escolhemos o campo da pedagogia do teatro como nosso ponto de vista. Segundo Ingrid Koudela:

[...] o termo pedagogia do teatro visou não apenas ampliar o espectro da pesquisa na área, trazendo para a discussão os Mestres do Teatro - dramaturgos, teóricos e encenadores, como também, fundamentar a epistemologia e os processos de trabalho em teatro, inserindo-os na história da cultura ${ }^{1}$.

Conduzir nosso olhar pelo campo pedagógico teatral significa traçar diálogos com educadores, artistas, alunos e demais envolvidos, percebendo seus pontos de intersecção na construção do fenômeno teatral e sua assimilação pelas instituições formadoras de atores, professores de teatro, diretores, cenógrafos e teóricos. Assim, focalizaremos as oficinas de teatro utilizadas pelos grupos na formação de atores e em projetos sociais.

Decifrar o cotidiano não é tarefa fácil para o pesquisador interessado em traduzir a dinâmica e a riqueza de um determinado processo pedagógico. Tal aventura implica numa disposição por parte do pesquisador em ampliar sua percepção de

${ }_{1}^{1}$ KOUDELA apud SANTANA, Arão Paranaguá (Coord.). Visões da Ilha: apontamentos em teatro e educação. São Luís: Grupo de Pesquisa em Ensino do Teatro \& Pedagogia Teatral, 2003. p. 17. 
uma determinada realidade "buscando referências de sons, sendo capaz de engolir sentindo a variedade de gostos, caminhar tocando as coisas e pessoas e [se] deixando tocar por elas, cheirando os odores que a realidade coloca em cada ponto do caminho diário" ". A apreensão dos modos de fazer e ensinar dos espaços cotidianos necessita de uma "parceria" entre os sujeitos da pesquisa, de forma a possibilitar a compreensão dos elementos presentes nestes modos, suas articulações, seus conteúdos e formas.

Como, então, poderemos compreender os procedimentos cotidianos em uso nas oficinas de teatro? Neste sentido, apoiamo-nos nos estudos de Michel de Certeau sobre as práticas cotidianas.

Certeau desenvolve as noções de estratégias e táticas:

[...] as estratégias são, portanto, ações que, graças ao postulado de um lugar de poder (a propriedade de um próprio), elaboram lugares teóricos (sistemas e discursos totalizantes), capazes de articular um conjunto de lugares físicos onde as forças se distribuem. Elas combinam esses três tipos de lugares e visam dominá-los uns pelos outros. Privilegiam, portanto, as relações espaciais [...]. As táticas são procedimentos que valem pela persistência que dão ao tempo - às circunstâncias que o instante preciso de uma intervenção transforma em situação favorável, à rapidez de movimentos que mudam a organização do espaço, às relações entre os momentos sucessivos de um "golpe", aos cruzamentos possíveis de durações e ritmos heterogêneos, etc. ${ }^{3}$.

Entender o cotidiano das oficinas de teatro é, assim, um trabalho que busca compreender as táticas utilizadas pelos ministrantes para seu fazer pedagógico, penetrando astuciosamente e de modo particular em cada momento.

Pela multiplicidade das práticas cotidianas, as mesmas, segundo Certeau, devem ser entendidas com um número finito de procedimentos, que aplicam os códigos e normas existentes numa determinada "ocasião", que resulta de um certo número de formalidades, diz ele:

Em primeiro lugar, os 'jogos’ específicos de cada sociedade [...] dão lugar a espaços onde os 'lances' são proporcionais a situações [...] os jogos 'formulam' as 'regras' organizadoras dos lances e constituem também uma 'memória' (armazenamento e classificação) de esquemas de ações articulando novos lances conforme as ocasiões. ${ }^{4}$

Sendo assim, as táticas utilizadas em uma situação específica possuem uma formalidade própria, que não permite o desvelamento do jogo em sua totalidade. As regras são sempre as mesmas, mas os lances, que são múltiplos, serão escolhidos pelo participante.

Adentrar no cotidiano das oficinas é a possibilidade que temos de perceber

\footnotetext{
${ }^{2}$ ALVES, Nilda. Decifrando o pergaminho: o cotidiano das escolas nas lógicas das redes cotidianas. In: OLIVEIRA, Inês; ALVES, Nilda (Org). Pesquisa no/do cotidiano das escolas sobre redes de saberes. Rio de Janeiro: DP\&A, 2001. p. 17.

${ }^{3}$ CERTEAU, Michel de. A invenção do cotidiano: artes do fazer. Petrópolis: Vozes, 1999. p. 102

${ }^{4}$ CERTEAU, 1999 , p. 83-84
} 
as escolhas táticas de cada artista-docente para o ensino do teatro, assim como de compreender os lances dos participantes em cada trabalho proposto.

\section{O que chamamos de oficina?}

Um primeiro ponto a ser tratado concerne à utilização da oficina de teatro como recurso pedagógico. $\mathrm{O}$ dicionário $A$ linguagem da cultura, produzido pelo SESC-SP, define assim o termo:

Oficina $-{ }^{5}$ 2) curso informal de breve duração ministrado para o aprendizado de uma técnica ou disciplina artística, sem objetivos oficialmente profissionalizantes; 4) laboratório (local ou recinto); em francês ateliê, em inglês workshop'.

Workshop - 1) termo inglês correspondente a oficina ou ateliê; 2) curso intensivo ou condensado nas áreas artística e esportiva; 3) experimentação de uma técnica ou de uma estética, principalmente nas áreas teatral e coreográfica, com a função de 'laboratório', ou seja, de pesquisa formal. Com esse sentido foram constituídas escolas de renome no séc. XX, como a Dramatic Workshop de NY, na qual trabalhou Erwin Piscator, o Theatre Workshop, da encenadora inglesa Joan Litlewoad ou o American Lyric Theatre Workshop, do centro de aprendizado e de criação de dança do coreógrafo Jerome Robbins. ${ }^{7}$

A oficina de teatro é um recurso amplamente utilizado nas atividades artístico-pedagógicas. Caracterizada como uma ação pedagógica ativista, em que o professor/oficineiro direciona as atividades de forma a estabelecer um exercício dialético entre o seu conhecimento e o que os participantes trazem de seu universo sociocultural. Nesta medida, a oficina torna-se um momento de experimentar, refletir e elaborar um conhecimento das convenções teatrais, buscando instrumentalizar os participantes de um conhecimento teatral básico, vivência de uma atividade artística que permite uma ampliação de suas capacidades expressivas e consciência de grupo. No caso dos grupos teatrais, valemos da observação de Argelander:

Historicamente, os workshops (oficinas) de teatro foram organizados dentro de uma estrutura flexível de atuação do grupo; o workshop em si mesmo funcionava com duas capacidades básicas: a primeira e mais importante, como um lugar para se livrar das classes dogmáticas de atuação no sentido de explorar novas idéias e, segunda, como forma prática de fazer produções que poderiam refletir mais os valores pessoais do grupo do que os valores padronizados do teatro comercial ${ }^{8}$.

As oficinas são estruturadas, quase sempre, por exercícios de voz, corpo, jo-

\footnotetext{
${ }^{5}$ Ateliê - estúdio, recinto ou local de aprendizado de técnicas e de criação de obras artísticas, equipado com ferramentas, máquinas e materiais adequados a uma ou várias expressões. CUNHA, Newton (Coord.). Dicionário SESC. A linguagem da cultura. São Paulo: SESC: Perspectiva, 2003. p. 81.

${ }^{6}$ CUNHA, 2003, p. 474.

7 CUNHA, 2003, p. 677.

8 ARGELANDER, Ron. Performance workshops: three types. Tradução de Zeca Ligiéro. TDR: The Drama Review, New York, v. 22, n. 4, p. 4, dez. 1978.
} 
gos e improvisação. Os jogos e as improvisações, elementos básicos no ensino do teatro, são utilizados nestes trabalhos, pois permitem que o material colhido na trajetória do grupo ou do artista seja apropriado e canalizado para o desenvolvimento da criatividade e expressão cênica dos participantes.

As oficinas de teatro oferecidas têm o objetivo de socializar elementos ideológicos e técnicos adquiridos e trabalhados pelo artista-docente em sua práxis artística ao longo de sua carreira. Nelas o pensamento ético e estético são incorporados às atividades pedagógicas e atores e encenadores vão assumindo o papel de artistas-docentes e assim, configurando uma pedagogia teatral.

\section{Alguns exemplos}

A Oficina de Experimentação e Pesquisa Teatral, desenvolvida pelo Oi Nóis Aqui Traveiz, objetiva descobrir novas formas de linguagem e elaborar encenações de intervenção social no cotidiano da cidade. Tal proposta surgiu da necessidade de experimentação e desmistificação da atividade teatral, enquanto especialidade de poucos, e da necessidade de discussão da própria realidade. Trabalha-se contínua e sistematicamente na elaboração de improvisações coletivas que serão apresentadas em ruas e parques da cidade.

Um outro exemplo, a oficina de despressurização do Grupo Tá na Rua, é assim descrita pela atriz e professora Ana Carneiro:

[...] as pessoas chegam, e o material já está na sala, disposto de modo a ser visto e encontrado com facilidade: máscaras, panos, roupas, perucas e outros objetos que favorecem a transformação, material já usado, doado ao grupo e que constitui seu patrimônio. São cores, brilhos, texturas que modificam os corpos, contribuem para a liberação dos sentimentos e estabelecem um estado de teatro, de representação, em relação a tudo que ali acontece, transformando em teatralidade/teatro os amores, as paixões, os ódios, os medos, a violência e tudo mais que aflora'.

Normalmente, as atividades artístico-pedagógicas de um grupo ficam a cargo de um membro específico, que terá a função de organizar pedagogicamente os materiais técnicos trabalhados por todos os integrantes ao longo de sua carreira. Em alguns casos, cada membro torna-se um especialista num determinado instrumental técnico e sua oficina será conduzida a partir dele. Desta forma, acreditamos que a dissociação entre a prática artística e a prática docente, muito comum no meio acadêmico, não alcança a mesma dimensão nas práticas pedagógicas dos grupos. Nestes, as esferas artística e pedagógica encontram-se interligadas, num processo recíproco de aperfeiçoamento.

A educadora e dançarina Isabel Marques, ao tecer considerações sobre a relação entre prática artística e prática pedagógica, propõe o conceito de artista-docente como uma prática educacional de integração entre estes dois universos, colocados como distintos, tanto por artistas como por educadores, mas integrados em sua

\footnotetext{
${ }_{9}$ CARNEIRO, Ana. Espaço cênico e comicidade: a busca de uma definição para a_linguagem do ator: Grupo Tá na Rua 1981. 1998. p. 66. Dissertação (Mestrado em Teatro) - Centro de Letras e Artes, UNIRIO, Rio de Janeiro, 1998.
} 
práxis na construção de um trabalho artístico-educativo, "não abandonando suas possibilidades de criar, interpretar, dirigir, [que] tem também como função e busca explícita a educação em seu sentido amplo"10.

\section{Considerações finais}

É nesta direção que trabalhamos na disciplina Prática de Ensino 3, com alunos do curso de teatro, modalidade licenciatura, da Universidade Federal de Uberlândia, discutindo, problematizando e experenciando a organização e feitura de uma oficina de teatro com conteúdos variados e para um público diversificado. Cada graduando apresenta seu pré-projeto de trabalho, que é discutido por todos, e que gradativamente vai se constituindo como um projeto final de execução. A única exigência que faço é que este projeto seja feito a partir do interesse pessoal do aluno sobre alguma técnica, escola ou procedimento teatral e esteja, de preferência, vinculado à sua prática artística ${ }^{11}$. Com isto, procuramos uma articulação entre a produção artística do licenciando e os procedimentos pedagógicos a serem acionados numa futura relação de ensino-aprendizagem, procurando romper com o velho chavão "quem sabe faz, quem sabe ensina" para uma nova perspectiva na formação do artista-educador "quem sabe faz e ensina".

\section{REFERÊNCIAS}

${ }_{10}$ MARQUES, Isabel. Ensino de dança hoje: textos e contextos. São Paulo: Cortez, 2001. p.112. 11 Cf. TELLES, Narciso; MASCARENHAS, Márcia. Trilhando os caminhos do menino-navegador: Ilo Krugli e o ensino de teatro. In: SANTANA, Arão Paranaguá (Coord.). Visões da Ilha: apontamentos em teatro e educação. São Luís: Grupo de Pesquisa em Ensino do Teatro \& Pedagogia Teatral, 2003. p. 61-74. 
ALVES, Nilda. Decifrando o pergaminho: o cotidiano das escolas nas lógicas das redes cotidianas. In: OLIVEIRA, Inês; ALVES, Nilda (Org.). Pesquisa no/do cotidiano das escolas sobre redes de saberes. Rio de Janeiro: DP\&A, 2001. p. 13-38.

ARGELANDER, Ron. Performance workshops: three types. Tradução de Zeca Ligiéro. TDR: The Drama Review, New York, v. 22, n. 4, p. 3-18, dez. 1978.

CARNEIRO, Ana. Espaço cênico e comicidade: a busca de uma definição para a_linguagem do ator: Grupo Tá na Rua 1981. 1998. 241p. Dissertação (Mestrado em Teatro) - Centro de Letras e Artes, UNIRIO, Rio de Janeiro, 1998.

CERTEAU, Michel de. A invenção do cotidiano: artes do fazer. Petrópolis: Vozes, 1999.

CUNHA, Newton (Coord.). Dicionário SESC. A linguagem da cultura. São Paulo: SESC: Perspectiva, 2003.

FERNANDES, José Nunes. Oficinas de música no Brasil. História e metodologia. Teresina: Fundação Cultural Monsenhor Chaves, 2000.

MARQUES, Isabel. Ensino de dança hoje: textos e contextos. São Paulo: Cortez, 2001.

SANTANA, Arão Paranaguá (Coord.). Visões da Ilba: apontamentos em teatro e educação. São Luís: Grupo de Pesquisa em Ensino do Teatro \& Pedagogia Teatral, 2003.

TELLES, Narciso; MASCARENHAS, Márcia. Trilhando os caminhos do menino-navegador: Ilo Krugli e o ensino de teatro. In: SANTANA, Arão Paranaguá (Coord.). Visões da Ilha: apontamentos em teatro e educação. São Luís: Grupo de Pesquisa em Ensino do Teatro \& Pedagogia Teatral, 2003. p. 61-74. 